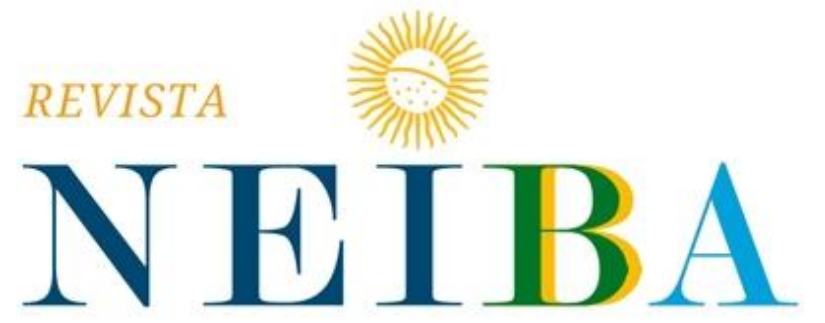

CADERNOS ARGENTINA-BRASIL
Volume 9, 2020, p. 01-19

DOI: 10.12957/neiba.2020.50646|e50646 I ISSN: 2317-3459

\title{
DO PRAGMATISMO AO UNIVERSALISMO: A MUDANÇA DE ESTRATÉGIA DA POLÍTICA EXTERNA BRASILEIRA PARA A AMÉRICA LATINA NO GOVERNO FIGUEIREDO (1979-1985)
}

FROM PRAGMATISM TO UNIVERSALISM: THE CHANGE IN STRATEGY OF BRAZILIAN FOREIGN POLICY FOR LATIN AMERICA UNDER THE FIGUEIREDO GOVERNMENT (1979-1985)

\section{Nathan Morais Pinto da Silva ${ }^{1}$}

\section{Álvaro Vicente Costa Silva²}

${ }^{1}$ Universidade do Estado do Rio de Janeiro (UERJ), Rio de Janeiro, RJ, Brasil. E-mail: nathan.morais@hotmail.com ORCID: https://orcid.org/0000-0002-6192-8158

${ }^{2}$ Universidade do Estado do Rio de Janeiro (UERJ), Nova Iguaçu, RJ, Brasil. E-mail: alvarovicentecosta@gmail.com ORCID: https://orcid.org/0000-0001-7006-3339

Recebido em: 01/01/2020 | Aceito em: 27/04/2020. 


\section{RESUMO}

Este artigo busca identificar e qualificar as mudanças da política externa brasileira para a América Latina no governo de João Figueiredo (1979-1985) em relação ao governo de Ernesto Geisel (1974-1979). O artigo é baseado no modelo proposto por Charles Hermann para mudanças em política externa. Serão considerados os quatro níveis graduados de mudança - ajuste, programa, objetivo e orientação internacional - e as quatro fontes de mudança - guiada pelo líder, burocracia, reestruturação doméstica, e choques externos - propostos pelo autor. Testaremos o modelo a partir de uma revisão de literatura que versa sobre as linhas gerais e específicas da política "universalista". Os dados indicam que ocorreu uma mudança de ajuste nas linhas gerais da política externa, mas, nas relações com a América Latina, houve uma mudança de objetivo. Argumenta-se também que tais mudanças foram impulsionadas pelo processo de redemocratização e gradual substituição do modelo de desenvolvimento econômico; além do impacto de choques externos.

Palavras-chave: Política externa brasileira; Mudanças em Política Externa; Governo Figueiredo.

\section{ABSTRACT}

This paper aims to identify and qualify the changes that occurred in the Brazilian Foreign Policy in João Figueiredo's presidency (1979-1985) in comparison to Ernesto Geisel's tenure as president (1979-1985). Our analysis is based upon Charles Hermann's framework to analyze changes in foreign policy. We consider his four graduated levels of change - adjustment, program, problem/goal, and international orientation - and his four sources of change - leader driven, bureaucratic advocacy, domestic restructuring, and external shocks. We test his framework through a literature revision about the "universalismo" general and specific lines. Our analysis points to adjustment changes in the foreign policy's general lines, but objective changes towards Latin America. We also argue that the sources of such changes were twofold: the domestic re-democratization process and the gradual replacement of the national economic development strategy; and external shocks impact.

Keywords: Brazilian foreign policy; changes in foreign policy; Figueiredo government. 
INTRODUÇÃO

O governo do general João Baptista de Oliveira Figueiredo teve início em 1979 e se encerrou em 1985, depois da eleição indireta de Tancredo Neves para a Presidência da República e a posse de seu vice, José Sarney, após seu falecimento. Os seis anos do governo Figueiredo marcaram um cenário de transição em meio a um processo de abertura e liberalização política que culminou no fim do regime militar que governara o Brasil desde 1964.

Quanto à atuação internacional do Brasil neste período, alguns autores utilizam a palavra "universalismo" para identificar o seu princípio norteador (Camargo, 1988; Gonçalves; Miyamoto, 1993). Um elemento que realça o tom de continuidade em relação ao período da política externa do Pragmatismo Responsável é a pontuação que o presidente João Figueiredo fez para Ramiro Saraiva Guerreiro, que seria seu chanceler, na primeira reunião de pauta entre eles. Conforme assinala o chanceler, Figueiredo "pretendia, em matéria de política externa, seguir a mesma linha geral do Governo anterior, porque achava que estava dando certo" (Guerreiro, 2010 [1985], p. 246).

Assim, a política externa de Figueiredo se orientou por três vetores: universalismo (busca de convivência harmoniosa no sistema internacional), dignidade nacional (resistência à tentativas de imposição de regras discriminatórias ou exclusivistas no sistema internacional) e boa convivência (com todos os países, sendo o respeito mútuo um padrão a ser seguido) $)^{3}$. observa-se a fidelidade ao paradigma globalista ${ }^{4}$ da política externa brasileira, inaugurado nos marcos da Política Externa Independente (19611964) dos governos Quadros e Goulart e retomado pelo governo de Geisel após uma abrupta interrupção durante os primeiros anos do regime militar.

O objetivo deste artigo é identificar a dimensão das mudanças na política externa de Figueiredo em relação ao seu antecessor, atribuindo um foco especial às relações do país com a América Latina. Tal análise será realizada a partir do artigo Changing course: when governments choose to redirect foreign policy (1990), de Charles Hermann, como

\footnotetext{
3 Ministério Das Relações Exteriores. Informação 021 ao Presidente da República, 29 mar 1979. Arquivo Saraiva Guerreiro, pasta SG mre 1979.03.20, CPDOC/FGV.

${ }^{4}$ Segundo o descrito por Lima (1994), conforme veremos a seguir.
} 
referencial teórico. No artigo em questão, Hermann apresenta quatro níveis graduados de mudança em política externa: mudanças de ajuste, programa, problema ou objetivo e orientação internacional (Hermann, 1990, p. 5); além de quatro fontes de mudança: mudança guiada pelo líder, pressão burocrática, reestruturação doméstica e choques externos (Hermann, 1990, p. 11-12).

A hipótese aqui proposta é de que no que diz respeito aos níveis de mudança, a política externa brasileira para a América Latina no governo Figueiredo passou por uma mudança de objetivo, mais intensa do que a mudança observada nas linhas gerais da política externa no período, que poderia ser caracterizada como mudança de ajuste. No que concerne às fontes de mudança, argumenta-se que pode ser identificado um processo de reestruturação doméstica, além da presença de choques externos.

Quanto à metodologia empregada, será realizado um teste de teoria a partir do modelo proposto por Hermann, tendo como estudo de caso a política externa brasileira para a América Latina no governo de João Figueiredo, entre os anos de 1979 e 1985. Será feita uma revisão de literatura a partir de artigos científicos e livros que versam sobre as linhas gerais e específicas da política externa brasileira do período, com a finalidade de identificar as ações e decisões referentes ao tema dentro do recorte temporal proposto.

Este artigo está dividido em cinco seções, além desta introdução. Primeiramente, será apresentado o modelo de análise dos níveis graduados e fontes de mudança em política externa de Charles Hermann. Na seção subsequente, serão discutidos os paradigmas históricos da inserção internacional do Brasil. Na terceira seção, será apresentado um breve histórico das linhas gerais da política externa brasileira nos governos antecedentes ao de Figueiredo, para então se proceder a uma discussão das distensões observadas no âmbito do governo em questão, sobretudo no que diz respeito à política externa brasileira para a América Latina. Por fim, serão apresentadas as conclusões extraídas a partir da análise aqui proposta.

\section{OS NÍVEIS E FONTES DE MUDANÇA EM POLÍTICA EXTERNA SEGUNDO HERMANN}

No artigo intitulado Changing course: when governments choose to redirect foreign policy (1990), uma das suas contribuições mais relevantes para o campo da Análise de 
Política Externa, Charles Hermann introduz um modelo de análise para as mudanças de política externa, sugerindo um conjunto de níveis graduados que quantificam a sua intensidade. Ademais, Hermann também identifica as diferentes fontes que originam essas mudanças. No mesmo artigo, o autor também propõe uma série de estágios do processo decisório que incorre nesses níveis e fontes de mudança.

Um dos argumentos principais propostos por Hermann no artigo é de que as mudanças de política externa e as mudanças de regime político ocorrem de forma separada. Segundo o autor, não necessariamente a mudança de regime é a única maneira de se observar mudanças drásticas na política externa de um país. Em certas ocasiões, o mesmo regime que implementa as políticas pode reconhecer que mudanças são necessárias (Hermann, 1990, p. 4). Os níveis graduados de mudança introduzidos por Hermann são: mudanças de ajuste, mudanças de programa, mudanças de problema ou objetivo e mudanças de orientação internacional (Hermann, 1990, p. 5).

As mudanças de ajuste representam uma alteração no nível de intensidade e/ou no escopo dos atores sob os quais a política em questão incide. As mudanças de programa representam uma mudança dos meios ou métodos pelos quais o problema é abordado ${ }^{5}$. Assim, o que é feito e como é feito muda, mas as motivações permanecem as mesmas. Quanto às mudanças de problema ou objetivo, essa situação é observada quando o problema ou objetivo inicial é substituído ou suprimido. Por fim, as mudanças de orientação internacional ocorrem quando se observa uma reorientação completa na atuação internacional do ator. Neste caso, ao contrário dos outros três níveis, não apenas uma, mas várias políticas são alteradas (Hermann, 1990, p. 5-6). Em seu artigo, Hermann utiliza como objeto de análise a política externa dos Estados Unidos na Guerra do Vietnã, argumentando que, em diferentes ocasiões, os quatro níveis de mudança foram observados no comportamento norte-americano durante o confronto.

Quanto às fontes de mudança, Hermann cita leader driven changes (mudanças guiadas pelo líder), bureaucratic advocacy (pressão burocrática), reestruturação doméstica e choques externos (Hermann, 1990, p. 11-12). A mudança guiada pelo líder é observada quando um líder autoritário - geralmente o chefe de governo - impõe sua

\footnotetext{
${ }^{5} \mathrm{O}$ autor cita como exemplo a substituição da força militar pela negociação diplomática na busca de um determinado objetivo (Hermann, 1990, p. 5).
} 
visão sobre o problema, causando a reorientação no comportamento externo do Estado. Nesse caso, o líder deve dispor de convicções, poder e energia para fomentar a mudança. Por sua vez, os cenários de pressão burocrática ocorrem quando um grupo que compõe o governo, localizando dentro de uma ou mais agências governamentais ou ministérios, advoga pela mudança. As mudanças por reestruturação doméstica ocorrem quando se observa uma mudança de composição ou das visões das elites que dispõem do poder de legitimar o governo, ou até mesmo quando existe uma mudança do próprio regime. Por fim, os choques externos são fontes de mudança resultantes de grandes eventos internacionais, em termos de impacto e visibilidade, acarretando a possibilidade de redirecionamento da política externa do país.

De acordo com Hermann, essas quatro fontes podem agir em conjunto, simultaneamente, ou uma pode causar a ativação da outra, causando mudanças de curso (Hermann, 1990, p. 12). O autor argumenta que, para ter efeito em uma mudança de política externa, os atores devem incidir no processo de formulação; e que o processo decisório em si pode obstruir ou facilitar a reorientação (Hermann, 1990, p. 13). Hermann situa o processo decisório num estágio intermediário entre as fontes de mudança, que servem como inputs, e os níveis graduados de mudança, que desempenham o papel de outputs.

Nas duas últimas seções deste artigo, serão analisadas as mudanças observadas na política externa brasileira durante o governo de Figueiredo (1979-85) em relação ao governo Geisel (1974-79), seu antecessor, tanto em linhas gerais quanto no que diz respeito às relações do Brasil com o resto do subcontinente latino-americano. Os quatro níveis graduados e as quatro fontes de mudança propostos por Hermann serão utilizados como referencial analítico, de modo que buscaremos enquadrar as mudanças observadas no período no modelo de análise formulado pelo autor.

\section{OS PARADIGMAS HISTÓRICOS DA POLÍTICA EXTERNA BRASILEIRA}

Antes de se proceder a uma contextualização histórica do período que será analisado, é necessária uma breve discussão acerca daqueles que são considerados os dois paradigmas históricos que orientam a formulação da política externa brasileira ao 
longo do período republicano (Lima, 1994; Pinheiro, 2004): o paradigma americanista, também conhecido como a "aliança especial", e o paradigma globalista.

De acordo com Maria Regina Soares de Lima (1994), o paradigma americanista deriva de diferentes interpretações do chamado "legado do Barão do Rio Branco". Nos marcos desse paradigma, os Estados Unidos são vistos como "uma potência global e hegemônica no hemisfério ocidental, e um eixo da política externa brasileira" (Lima, 1994, p. 35). Os defensores dessa corrente defendem a tese de que, devido à hegemonia norte-americana no hemisfério, o alinhamento aos Estados Unidos aumentaria o poder de barganha brasileiro no sistema internacional. Letícia Pinheiro (2004) sustenta que o paradigma americanista pode ser dividido em duas vertentes: a ideológica e a pragmática.

O americanismo ideológico, observado no contexto do imediato pós-Segunda Guerra no governo Dutra (1946-51) e após o golpe militar que empossou o general Castello Branco (1964-67), parte de "fatores de ordem normativa e de uma suposta convergência ideológica entre brasileiros e norte-americanos que justificavam a aliança aos Estados Unidos" (Pinheiro, 2004, p. 65). Por outro lado, o americanismo pragmático representaria, segundo a autora, o "aproveitamento das oportunidades da aliança com Washington, cuja efetivação teria natureza predominantemente instrumental". O americanismo pragmático foi observado desde os dias de Rio Branco até a Segunda Guerra Mundial (1902-45), no segundo governo Vargas e no governo Kubitschek (195161) e, durante o regime militar, nos governos Costa e Silva e Médici (1967-74).

No que diz respeito ao paradigma globalista, Lima localiza suas origens nas ideias articuladas pelo embaixador Araújo Castro - destacando-se entre elas a tese do "congelamento do poder mundial" ${ }^{6}$ - no final da década de 50 e início da década de 60, sob marcante influência das críticas nacionalistas à orientação americanista da política externa brasileira presente nos estudos desenvolvidos no âmbito do Instituto Superior de Estudos Brasileiros (ISEB) sob a liderança de Hélio Jaguaribe. Ademais, o paradigma globalista se inspira na visão das relações centro-periferia da Comissão Econômica para

\footnotetext{
${ }^{6}$ Por "congelamento do poder mundial", Castro se refere ao esforço conjugado das duas superpotências globais da época, os Estados Unidos e a União Soviética, de imobilização da ordem internacional no pós-Segunda Guerra, a partir de instrumentos como a Carta das Nações Unidas e o Tratado de Não-Proliferação Nuclear (Castro, 1972, p. 12).
} 
a América Latina das Nações Unidas (CEPAL), sobretudo no pensamento do economista argentino Raúl Prebisch (Lima, 1994, p. 35-36). O paradigma globalista foi observado na política externa brasileira pela primeira vez nos marcos da Política Externa Independente dos governos de Jânio Quadros e João Goulart, quando Araújo Castro desempenhou a função de chanceler.

Quanto à sua tipificação, Letícia Pinheiro argumenta que o paradigma globalista pode ser dividido em um de base hobbesiana e outro de base grotiana, fazendo referência às ideias dos pensadores políticos Thomas Hobbes e Hugo Grotius, respectivamente. O globalismo hobbesiano consideraria a suposição de um sistema internacional anárquico guiado pelo princípio da autoajuda, enquanto o globalismo grotiano levaria em conta a ideia de que os Estados não buscam apenas ganhos relativos, mas também ganhos absolutos (Pinheiro, 2004, p. 66). De acordo com a autora, o globalismo hobbesiano foi observado desde o governo Geisel até a crise dos paradigmas situada no governo Collor (1974-90), enquanto o globalismo grotiano se materializou apenas durante a Política Externa Independente dos governos Quadros e Goulart (1961-64).

Portanto, após essa breve identificação dos paradigmas americanista e globalista, pode-se inferir que as eventuais mudanças de paradigma observadas na história da política externa brasileira podem ser classificadas como mudanças de orientação internacional segundo o modelo de análise proposto por Hermann. Dois exemplos desse nível de mudança são a substituição do paradigma globalista pelo americanista pelo governo Castello Branco após o golpe militar de 1964; e a reversão dessa mudança, que se iniciou no governo Costa e Silva, e ficou mais marcante a partir do governo Geisel, sendo consolidada no governo Figueiredo.

\section{A POLÍtICA EXTERNA DO REGIME MILITAR E A CONSOLIDAÇÃO DO PARADIGMA GLOBALISTA}

O golpe militar de 1964 representou uma ruptura com o paradigma globalista da Política Externa Independente, por meio da implementação de uma nova estratégia de 
política externa inspirada nas ideias desenvolvidas por Golbery do Couto e Silva ${ }^{7}$ no âmbito da Escola Superior de Guerra (ESG). Tais deias continham um forte teor nacionalista, pautado na ideia do Brasil como potência mundial, e anticomunista, aderindo à lógica da Guerra Fria (Gonçalves; Miyamoto, 1993, p. 213-214). O binômio "segurança e desenvolvimento" (Gonçalves; Miyamoto, 1993, p. 216) passou a constituir a base ideológica da política externa brasileira no governo Castello Branco, no sentido de que a segurança nacional seria uma condição fundamental para o desenvolvimento. Contudo, essa guinada radical em direção ao americanismo não durou muito, pois já no governo Costa e Silva é possível observar alguns movimentos de redirecionamento ao paradigma globalista.

Gonçalves e Miyamoto (1994) argumentam que o governo Costa e Silva promoveu a inversão do binômio que permeou a atuação internacional do Brasil no governo anterior, com a segurança sendo concebida como um produto do desenvolvimento. Assim sendo, a superação do subdesenvolvimento pelos países terceiro-mundistas seria um objetivo do interesse nacional brasileiro. De acordo com Martins (1975), a "diplomacia da prosperidade" de Costa e Silva fez com que o Brasil assumisse "uma posição de relativa confrontação com os países industrializados e de solidariedade militante com os países do Terceiro Mundo, em geral, e os países latino-americanos, em particular" (Martins, 1975, p. 71-72), o que pode ser confirmado ao considerarmos ações como a recusa brasileira ao assinar o Tratado de Não-Proliferação Nuclear, em 1967, e a liderança do país na II Conferência de Comércio e Desenvolvimento das Nações Unidas (UNCTAD), em 1968.

A "diplomacia do interesse nacional" do governo Médici demonstrou algum grau de continuidade em relação ao governo anterior, mas com uma diferença no que diz respeito aos instrumentos utilizados na busca pelo desenvolvimento. De acordo com Gonçalves e Miyamoto (1998, p. 225), foi atribuída no governo Médici uma maior prioridade às relações bilaterais em detrimento dos esforços coletivos do Terceiro Mundo na busca da superação do subdesenvolvimento. Nesse contexto, caberia ao Brasil, em meio a um processo de crescimento econômico acelerado (que viria a ficar

\footnotetext{
${ }^{7}$ Sobre o pensamento do General Golbery do Couto e Silva e da Escola Superior de Guerra acerca da inserção internacional brasileira, ver Couto e Silva (1967).
} 
conhecido como o "milagre econômico"), desempenhar um papel de interlocutor entre as grandes potências e os países em desenvolvimento.

Apesar dos esforços empreendidos nos governos anteriores, somente no governo Geisel pode ser observada a reorientação total da política externa brasileira na direção do paradigma globalista. Com o fim do milagre econômico dos anos Médici, a economia brasileira passa por um período de crescimento em "marcha forçada" 8 , guiado pelo II Plano Nacional de Desenvolvimento. A política externa tinha um papel central na consecução desse plano, incentivando a diversificação de parcerias e a universalização das relações internacionais do país, como parte de uma tentativa de se manter o nível de crescimento econômico observado no governo anterior como parte de um "projeto de Brasil potência emergente" (Saraiva, 1998). O termo "pragmatismo ecumênico e responsável", cunhado pelo próprio Geisel, foi escolhido para designar o período dentro da historiografia da política externa brasileira.

Em sua tese de doutorado, Letícia Pinheiro fornece uma explicação para o termo escolhido, definindo seus três componentes: "pragmatismo" pois se rejeitava o compromisso com princípios ideológicos que pudessem interferir na busca pelo interesse nacional; "ecumênico" pois a política externa do período buscava levar em conta todas as possibilidades na formulação da atuação internacional do país; e "responsável" pois buscava se adaptar às expectativas dos apoiadores do regime, nos marcos de uma política de liberalização "lenta e gradual” (Pinheiro, 2013, p. 120-121).

Foi no governo Geisel, através da atuação do chanceler Antônio Azeredo da Silveira, que o Brasil estabeleceu relações diplomáticas com a República Popular da China. Além disso, o Brasil também se aproximou dos países árabes exportadores de petróleo e reconheceu as independências de Angola, Moçambique e Guiné-Bissau, excolônias portuguesas na África, marcando uma distensão no alinhamento com Portugal, vigente até então. Quanto aos padrões de formulação da política externa no período, Pinheiro (2000, p. 463-464) afirma que uma relação de "extrema proximidade" entre

\footnotetext{
${ }^{8}$ O termo "marcha forçada", na concepção de Antonio Barros de Castro e Francisco Pires de Souza, se refere ao processo de retomada do crescimento econômico brasileiro após o fim do milagre econômico. Para mais, ver Castro (2004).
} 
Geisel e Azeredo da Silveira, pautada numa "forte convergência de opiniões", forneceu as bases para as linhas gerais da política externa brasileira no período.

De acordo com Paulo Visentini (2004, p. 226), durante o período Geisel, "a agenda latino-americana parece ter se situado num plano inferior" quando em comparação com a Europa ocidental, região mais visitada pelo presidente. Enquanto isso, no plano do discurso, a região ainda era considerada o foco principal da política externa brasileira. Ainda segundo o autor, o Brasil buscava dois tipos de objetivos no contexto latino-americano, de acordo com o grau de desenvolvimento dos seus contrapartes: com as "potências médias" da região, o país buscava iniciativas de cooperação comercial e técnica; enquanto que em relação aos países de menor grau de desenvolvimento relativo - como Uruguai, Paraguai e Bolívia -, o Brasil desempenhava ações de cooperação assistencial no plano tecnológico e financeiro, por meio de um viés "comercial-estratégico" (Visentini, 2004, p. 228).

Contudo, havia fragilidades no componente latino-americano do pragmatismo responsável de Geisel. Os países vizinhos enxergavam a assertividade da política externa brasileira no período com desconfiança, graças a uma imagem percebida de um Brasil "movido por apetites hegemônicos" (Gonçalves; Miyamoto, 1998, p. 235), acusações que foram rebatidas de forma enfática por Silveira. Antes mesmo de sua assunção como chanceler, em 1971, quando atuava como embaixador em Buenos Aires, Silveira lidava com acusações argentinas de um Brasil "imperialista" e acusador de uma "liderança" brasileira", movidas pelo avanço no projeto de empreendimentos hidrelétricos de Sete Quedas/Itaipu.

A questão do projeto hidrelétrico de Itaipu era um ponto delicado nas relações do país com a Argentina, que via o projeto como uma estratégia brasileira de dominação geopolítica na Bacia do Prata. Miriam Saraiva (2012) usa o termo "rivalidade assimétrica" (p. 56) para caracterizar as relações entre Brasil e Argentina no período, graças às assimetrias de poder econômico e político -internacional e regionalpercebidas por parte do Brasil no âmbito da relação entre os países. O Peru foi outro país vizinho cujas relações com o Brasil se estremeceram no período. Nas palavras de

\footnotetext{
${ }^{9}$ Embaixada Do Brasil Em Buenos Aires. Telegrama no 1237, expedido ao Ministério de Relações Exteriores, Brasília, em 26 jul 1971 (Secreto-urgentíssimo). Arquivo Azeredo da Silveira, pasta AAS eba 1969.01.15, CPDOC/FGV.
} 
Visentini (2004), o governo peruano de Velasco Alvarado era um "regime suspeito para o governo brasileiro" (p. 231) e, ainda que houvesse concordâncias em certas questões, as divergências entre os países quanto à questão cubana e ao Movimento dos NãoAlinhados dificultavam o entendimento entre os dois países.

A despeito das desconfianças, também podem ser observados êxitos na política externa de Geisel para a região, sobretudo em suas bases comerciais e no âmbito multilateral. Um exemplo disso é a assinatura do Tratado de Cooperação Amazônica em conjunto com Bolívia, Peru, Equador, Colômbia, Venezuela, Guiana e Suriname, em 1978. Foi um importante reconhecimento da importância dos países da Bacia Amazônica ao Brasil, pois conforme reconheceu Silveira, "as relações bilaterais com os vizinhos amazônicos, exceção feita da Bolívia, pautavam-se por linhas de amizade meramente declaratória" ${ }^{10}$. Em meio ao avanço do desenvolvimento econômico brasileiro, naturalmente, uma nova posição junto aos vizinhos da Bacia Amazônica era demandada.

Além disso, foram observados avanços nas relações bilaterais com os países do continente, com destaque para os acordos sobre comércio de carvão e minério de ferro com a Colômbia assinados em 1976. A intensificação das relações com a Venezuela, motivada pelo primeiro choque do petróleo; e a visita de Geisel ao México, com a assinatura de acordos e convênios nos campos industrial e financeiro com aquele país em 1978, configuraram outros dois avanços na América do Sul. A assinatura de diversos acordos de cooperação técnica com países da América Central e do Caribe, como Honduras, Guatemala e Trinidad e Tobago; a criação da Comissão Mista Brasil-Guiana e o início das relações diplomáticas com o Suriname, que conquistou sua independência dos Países Baixos em 1975, também foram marcos (Visentini, 2004, p. 231-233).

\section{O UNIVERSALISMO DO GOVERNO FIGUEIREDO E A VIRADA PARA A AMÉRICA LATINA}

O governo de Figueiredo marcou a etapa final do processo de liberalização política do país, fornecendo as bases para a conversão do regime político brasileiro em uma democracia plena. A consolidação do paradigma globalista da política externa,

\footnotetext{
${ }^{10}$ Ministério Das Relações Exteriores. Informação para o Senhor Presidente da República, expedida pelo Ministério de Relações Exteriores, em 04 mar 1976. Arquivo Azeredo da Silveira, pasta AAS mre ai 1977.03.02. CPDOC/FGV.
} 
materializado na continuação das linhas gerais do pragmatismo responsável de Geisel, fazia parte desse processo de transição. Nas palavras de Gonçalves e Miyamoto (1994, p. 237), "o que antes fora apresentado como pragmatismo agora consolidava-se como uma estratégia articulada e coerente". Isso justificaria a substituição do termo "pragmatismo" por "universalismo" na caracterização histórica do período, atribuindo um sentido de continuidade e permanência ao modelo de inserção internacional do país.

As condições internacionais, entretanto, não eram mais as mesmas do período do Pragmatismo Responsável. Além do segundo choque do petróleo, ocorrido em 1979, outro fator de inflexão foi a saída de Jimmy Carter e a ascensão de Ronald Reagan à presidência dos EUA. Tal inflexão seria marcada por um elemento: o esforço estadunidense pela retomada de sua hegemonia. Tal contexto envolveu o aumento de juros do Federal Reserve Board para conter a inflação estadunidense, fenômeno que se conjugou com a retração do crédito aos países em via de desenvolvimento (PVD), inviabilizando a estratégia do desenvolvimento via endividamento (Tavares, 1985). O déficit da conta corrente brasileira atingira 12,7 bilhões de reais, e as reservas cambiais esvaíam-se (Carneiro; Modiano, 2014, p. 263-264).

Tais choques externos demandaram um esforço exportador maior, de modo a atenuar o estrangulamento da balança de pagamentos. Além disso, estimulou ajustes na política externa: em termos gerais, a linguagem abandonou a ideia de "Brasil Potência" (limitadora da ação internacional e geradora de desconfianças na América Latina); em termos específicos, mudanças para a América Latina, com busca de recuperação da "identidade latino-americana" e incrementar o relacionamento com os países vizinhos (Lima; Moura, 1982). Era o estímulo para ir além de um uso "instrumental" do relacionamento com a América Latina, algo que Saraiva (2012) aponta como o processo de "latinoamericanização" da política externa brasileira.

No que se refere ao processo decisório na política externa brasileira no governo em questão, é possível observar um menor grau de envolvimento direto do Presidente da República, ao contrário do período anterior. De acordo com Pinheiro (2000), "Figueiredo não coordenava de maneira tão criteriosa os assuntos de natureza 
internacional, não assumia a função de árbitro de disputas burocráticas, nem compunha com seu chanceler uma parceria especial" (p. 467), diferente do que era observado com Geisel e Silveira. Uma exceção foi a relação com a Argentina, de notória saliência para Figueiredo. A resolução da questão de Itaipu e a melhora das relações com a Argentina era prioridade ao presidente, que afirmou que "se fosse necessário iria a Buenos Aires" (Guerreiro, 2010 [1985], p. 246).

A chancelaria do embaixador Ramiro Saraiva Guerreiro abriu embaixadas na África, estabeleceu acordos de cooperação com China, Japão e países do Oriente Médio e estreitou laços diplomáticos com países europeus, reforçando assim seu caráter universalista e dando continuidade à guinada em direção ao paradigma globalista iniciada pelo governo Geisel. De acordo com Visentini (2004, p. 277), não se tratava de uma mudança de trajetória, mas "somente uma adaptação aos novos ambientes externo e interno, leia-se a crise da dívida e a Nova Guerra Fria e o processo de abertura e crise político-econômica do regime".

Miriam Saraiva (2012, p. 59-60), por sua vez, argumenta que devido ao fato do "projeto de Brasil potência emergente" ter sido descontinuado graças à conjuntura internacional e ao contexto interno, a política externa brasileira passou por adaptações. Assim, em se tratando das suas linhas gerais, é possível caracterizar a mudança da política externa brasileira no governo Figueiredo como uma mudança de ajuste, nos termos do modelo de análise proposto por Hermann apresentado na primeira seção do artigo.

Diferente do governo anterior, a América Latina - a exceção de Cuba, cujas relações diplomáticas com o Brasil só foram normalizadas no governo de José Sarney, em 1986 - desempenhou um papel central na política externa brasileira do governo Figueiredo. Nas palavras de Visentini (2004, p. 293), o componente ocidentalista e terceiro-mundista da política externa brasileira do período "previa, como eixo prioritário, o fortalecimento da opção pela América Latina".

Um exemplo foi a busca pela superação de eventuais desconfianças remanescentes nos vizinhos em relação ao Brasil. Isso veio através de iniciativas de integração regional latino-americana, por meio do apoio à criação da Associação Latino-Americana de 
Integração (ALADI), em substituição à ALALC, e da Organização Latino-Americana para o Desenvolvimento (OLADE), voltada para a cooperação energética. O país também participou do Grupo de Cartagena, formado com a finalidade de tratar do problema da dívida externa dos países latino-americanos. A questão hidrelétrica teve, por fim, sua solução após anos de negociação, com a assinatura do Acordo Tripartite Itaipu-Corpus em conjunto com Argentina e Paraguai, em outubro de 1979.

A solução da questão hidrelétrica foi de importância fundamental para a normalização das relações entre Brasil e Argentina. O país vizinho deixaria de ser visto como um adversário geopolítico na América do Sul para ser percebido como um parceiro estratégico, com um lugar de destaque e alta prioridade nas relações internacionais brasileiras. Ainda no governo Figueiredo, foram assinados diversos acordos entre os dois países, com destaque para o campo da cooperação nuclear, que eventualmente forneceria as bases para a construção de um mecanismo conjunto de cooperação técnica nessa matéria nos anos seguintes (Saraiva, 2012, p. 62-63).

Quanto à questão das Ilhas Malvinas, invadidas pela Argentina em 1982, o Brasil agiu com o intuito de preservar as boas relações com os dois lados envolvidos no conflito. Nas palavras do próprio Saraiva Guerreiro, o objetivo era "atravessar a tensão e os riscos criados, sem destruir a nova fase de excelentes reações com a Argentina, que iniciara, nem criar um dano sensível a suas relações com a Grã-Bretanha" (Guerreiro, 1992, p. 103). As boas relações com o governo de Buenos Aires se mantiveram por todo o governo de Figueiredo, até mesmo durante o “ano atípico" ${ }^{11}$ de 1984, quando o Brasil foi governado por um militar e a Argentina, por um presidente civil, Raúl Alfonsín.

Quanto às relações com os outros países da América do Sul, observa-se um quadro de estabilidade. Foram assinados acordos de cooperação energética e em infraestrutura com o Uruguai e com o Paraguai, com destaque para os avanços na construção do complexo hidrelétrico de Itaipu em conjunto com este último. No que diz respeito às relações com o Chile, o Brasil optou por uma "orientação de não-ativismo" (Visentini,

\footnotetext{
11 João Figueiredo e Raúl Alfonsín coincidiram como presidentes de Brasil e Argentina, respectivamente, entre dezembro de 1983 e janeiro de 1985. Esse período de 14 meses é caracterizado por Miriam Saraiva como "ano atípico" (Saraiva, 2012, p. 67).
} 
2004, p. 305) em relação ao regime de Augusto Pinochet, ainda que mantendo relações de amizade no âmbito comercial.

A Venezuela também desempenhou um papel relevante na política externa brasileira no período, sobretudo graças à importância das suas exportações de petróleo para o Brasil. O país foi o destino da primeira visita presidencial de Figueiredo, em novembro de 1979, quando foram assinados tratados de cooperação. De acordo com o chanceler, essa visita continha um sentido implícito, se tratando de um vizinho governado por um regime democrático (Guerreiro, 1992, p. 125).

Iniciativas de aproximação no âmbito comercial e da integração regional com a Colômbia, Peru e Bolívia também foram realizadas (Visentini 2004, p. 310-311). As relações brasileiras com as Guianas também foram transformadas, por meio de acordos de importação de bens e serviços foram firmados com a Guiana e o Suriname. Com o governo surinamês, o Brasil firmou acordos de cooperação militar e optou por manter as relações com o país após o golpe militar em Paramaribo no ano de 1981 (Visentini, 2004, p. 312-313).

No que diz respeito à atenção atribuída à América Central e ao Caribe, cabe destacar que o Brasil demonstrou apoio ao Grupo de Contadora, esforço de concertação política na América Central formado em 1982 e composto por México, Panamá, Colômbia e Venezuela. No ano de 1979, o Brasil rompeu relações com o regime de Somoza, na Nicarágua. A questão cubana ainda era uma pauta delicada para a política externa brasileira. Como lembra Visentini (2004, p. 317), as divergências observadas nos segmentos militares do governo e no Congresso atrasaram a normalização das relações com o governo de Havana, que só ocorreu no governo Sarney. Contudo, nas palavras de Guerreiro (1992, p. 146), "houve uma redução de agressividade verbal" por parte do Brasil, e os fluxos de comércio entre os países se intensificaram, através de um regime de "comércio por triangulação".

\section{CONCLUSÃO}

Os anos do governo Figueiredo marcaram um período de profundas transformações, tanto no contexto interno da política nacional quanto no cenário internacional. A crise do modelo desenvolvimentista ocorria em concomitância com o 
processo de liberalização política e fim do regime militar, ocasionando uma desaceleração no crescimento econômico brasileiro e o fim do "projeto de Brasil potência emergente" iniciado com o milagre econômico dos anos Médici e continuado pelo governo Geisel. No plano externo, a Guerra Fria chegava ao seu estágio derradeiro, e era observado o nascimento de uma "nova ordem econômica internacional". Evidentemente, essas transformações internas e externas causariam reflexos na condução da política externa do país. A intenção desse artigo é evidenciar e qualificar tais distensões a partir de uma fundamentação teórica consolidada.

Ao se analisar a política externa do governo Figueiredo em comparação com o seu antecedente Geisel, observa-se certa continuidade em relação às suas linhas gerais. O caráter pragmático e ecumênico se mantém, bem como o compromisso com o processo de liberalização política. Não restam dúvidas, portanto, de que se observa a manutenção do paradigma globalista, e, consequentemente, da orientação internacional do país. Também não é possível dizer que há uma mudança de problema ou objetivo, pois o desenvolvimento econômico do país ainda compõe o núcleo duro da estratégia da política externa brasileira. A classificação mais apropriada para a mudança nas linhas gerais da inserção internacional do Brasil no governo de Figueiredo é, então, a de mudança de ajuste, pois não são observadas alterações significativas nos métodos e objetivos da orientação internacional do país no período.

Contudo, ao direcionarmos a discussão para as relações do país com a América Latina no período, é possível observar uma mudança de objetivo, tendo em vista que não apenas os métodos de abordagem utilizados pela política externa brasileira em relação aos seus vizinhos se modificaram, mas também a posição que a América Latina ocupava no rol de prioridades da atuação internacional do Brasil à época.

O Brasil passou a apoiar e até mesmo liderar iniciativas de integração regional e econômica no continente, patrocinar mecanismos de concertação política, coordenar projetos conjuntos de infraestrutura e reforçando laços com vizinhos que se tornariam parceiros estratégicos após um longo período de desconfianças, como pode ser observado no caso das relações com a Argentina após a solução da questão ItaipuCorpus. Assim sendo, a América Latina deixou de ocupar uma posição distante do 
centro das atenções - como era o caso no governo Geisel - para se consolidar como a região mais importante da política externa brasileira no governo Figueiredo.

Por fim, cabe aqui a discussão sobre as fontes das mudanças na política externa brasileira do período. O tipo de mudança causado por reestruturação doméstica pode ser citado, tendo em vista que o Brasil passava por um processo de transição de regime político e pela gradual substituição de seu modelo de desenvolvimento, o que demandava ajustes e novas abordagens na condução da política externa. Ademais, podemos também identificar choques externos, como a transformação da ordem econômica mundial decorrente dos últimos anos da Guerra Fria, o que impulsionou mudanças nas relações internacionais do país, como uma defesa mais enfática do multilateralismo e da integração regional.

\section{REFERÊNCIAS}

Camargo, S. (1988). Autoritarismo e democracia na Argentina e Brasil: uma década de política exterior - 1973-1984. São Paulo: Editora Convívio.

Carneiro, D.; Modiano, E. (2014). 'Ajuste externo e desequilíbrio interno, 1980-1984', in: Abreu, M. (org.) A ordem do progresso: dois séculos de política econômica no Brasil, 2a ed. Rio de Janeiro: Elsevier, pp. 263-280.

Castro, A. (2004). A economia brasileira em marcha forçada - 4ạ edição. São Paulo: Paz e Terra.

Castro, J. (1972). 'O congelamento do Poder Mundial', in: Revista Brasileira de Estudos Políticos, n. 33, pp. 7-30.

Couto e Silva, G. (1967). Geopolítica do Brasil. Rio de Janeiro: José Olympio Editora.

CPDOC/FGV. (1969). Arquivo Azeredo da Silveira, pasta AAS eba 1969.01.15.

(1977). Arquivo Azeredo da Silveira, pasta AAS mre ai 1977.03.02.

(1979). Arquivo Saraiva Guerreiro, pasta SG mre 1979.03.20.

Gonçalves, W; Miyamoto, S. (1993). 'Os militares na política externa brasileira: 19641984', Estudos Históricos, 6(12), pp. 211-229 (246).

Guerreiro, R. (1992). Memórias de um Empregado do Itamaraty. São Paulo: Siciliano.

Hermann, C. (1990). 'Changing course: when governments choose to redirect foreign policy', International Studies Quarterly., 34(1), pp. 3-21. 
Lima, M. de. (1994). 'Ejes analíticos y conflicto de paradigmas en la política exterior brasileña', América Latina/Internacional, 1(2), pp. 27-46.

; Moura, G. (1982). 'A trajetória do pragmatismo: uma análise da política externa brasileira'. Dados, 25(3), pp. 349-363.

Martins, C. (1975). 'A evolução da política externa brasileira na década 64/74'. Estudos Cebrap, n.12, pp. 55-98.

Pinheiro, L. (2000). 'Unidades de decisão e processo de formulação de política externa durante o regime militar', in: Albuqerque, J. A. G. de. Sessenta anos de política externa brasileira (1930-1990): Prioridades, Atores e Políticas. São Paulo: Annablume/Nupri, pp. 449-462.

. (2004). Política externa brasileira (1889-2002). Rio de Janeiro: Jorge Zahar

Editor.

. (2013). Foreign policy decision-making under the Geisel Government: the president, the military and the foreign ministry. Brasília: Fundação Alexandre de Gusmão.

Saraiva, M. (1998). 'Política externa, política interna e estratégia de desenvolvimento: o projeto de Brasil potência emergente (1974 a 1979)', Sociedade em Debate, 4(1), pp. 19-38.

. (2012). Encontros e desencontros: o lugar da Argentina na política externa brasileira. Belo Horizonte: Editora Fino Traço.

Tavares, M. (1985). 'A retomada da hegemonia norte-americana'. Revista de Economia Política. 5(2), pp. 5-15.

Visentini, P. (2004). A política externa do regime militar brasileiro: multilateralização, desenvolvimento e construção de uma potência média (1964-1985). Porto Alegre: Editora da UFRGS. 